\title{
Influence of High Osmotic Pressure on Sorbitol Production by Zymomonas mobilis
}

\author{
Josiane Alessandra Vignoli $^{1^{*}}$, Marcia Luciana Cazetta ${ }^{1}$, Rui Sérgio Santos Silva ${ }^{1}$ and \\ Maria Antonia Pedrine Colabone Celligoi ${ }^{2}$ \\ ${ }^{I}$ Departamento de Tecnologia de Alimentos e Medicamentos; Centro de Ciências Agrárias; Universidade Estadual \\ de Londrina; Londrina - PR - Brasil. ${ }^{2}$ Departamento de Bioquímica; Centro de Ciências Exatas; Universidade \\ Estadual de Londrina; Londrina - PR - Brasil
}

\begin{abstract}
The objective of the present work was to study the variation on the sorbitol production in relation to the concentration of sugars, (metabolizable or not) and the cultivation time. A full factorial design was used considering the factors such as sucrose and maltose concentration and cultivation time. The addition of sugars caused increases on the sorbitol production up to the concentration of $300 \mathrm{~g} / \mathrm{L}$ however, decreases on the sorbitol production were observed when the concentration reached values above this. Increasing the time of fermentation was statistically significant to sorbitol production, however, little increase the production was noticed after $36 h$.
\end{abstract}

Key words: Zymomonas mobilis, sorbitol, high osmotic stress, maltose

\section{INTRODUCTION}

Zymomonas mobilis produces ethanol through the Entner-Doudoroff route in conjunction with pyruvate decarboxylase and alcohol dehydrogenase enzymes. It catabolizes only Dglucose, D-fructose and sucrose as sources of carbon and energy (Swings and De Ley, 1977). Ethanol and carbon dioxide are the main products obtained from the catabolism when cells grow anaerobically in glucose medium. However, in sucrose-based substrates, ethanol production may be reduced up to $70 \%$ due to the formation of byproducts such as levan and sorbitol (Viikari, 1984; Viikari, 1986; Kannan, et al, 1998). Sorbitol is also formed and appears in the medium when cells grow in mixtures composed of glucose and fructose exceeding 5\% of sugarcane (Sprenger, 1996).

When growing in sucrose medium, Z. mobilis converts the disaccharide into glucose and fructose with the aid of three enzymes: extracellular levansucrase (Lev U), forming glucose and fructose that are converted into levan, a extracellular invertase or sucrase (Inv B) that releases glucose and fructose (Preziosi and Barati, 1990; O'Mullan et al, 1991; Yanase, et al, 1992) and a second invertase (Inv A) whose exact function and location in Z. mobilis are not fully understand. After the fructose release, sorbitol may be produced by the action of the GFOR enzyme, which is an enzyme located at the $Z$. mobilis periplasmatic region (Aldrich, et al, 1992; Loos et al, 1991; Loos et al, 1993; Loos et al,

*Author for correspondence: josivignoli@yahoo.com.br 
1994) and capable of converting the mixtures of glucose and fructose into gluconate- $\delta$-lactone and sorbitol, respectively. Sorbitol is mainly produced under high sucrose concentration conditions, where fructose accumulates favorably at high levels (Doelle et al, 1990; Rogers and Lee, 1982), requiring a sorbitol cell osmoprotection. A stressing condition that may be due to the high concentration of sugar in the medium or due to the presence of sugars not transported or metabolized such as maltose, makes the cells to accumulate intracellular sorbitol at concentration above $1 \mathrm{M}$ in order to neutralize the dehydration effects of the high external osmolality (Loos et al, 1994).

In order to corroborate the osmoprotective effect of sorbitol, Wiegert et al. (1996) worked with a non sorbitol-producing glucose-fructoseoxidoreductase-deficient mutant strain and observed that this strain was not able to grow in the presence of $1 \mathrm{M}$ of sucrose unless sorbitol was added to the medium. Savvides et al (2000) studied mutant strains capable of growing in high concentrations of sugars ( $40 \%$ of sucrose) and considered that such capacity could be also attributed to a differentiated fatty acids and phospholipids composition in the membrane.

However, studies on the effect of the medium osmolality on the $Z$. mobilis metabolism are scarcely found in literature (Lin et al, 1991). In this context, changes on the medium osmolality must be considered as a promising way to induce the controlled metabolic readjustments in order to provide higher knowledge on the Z. mobilis physiological control in the attempt of reaching more satisfactory production levels (Vigants et al, 1996). Thus, the objective of this work was to study the effect of the medium osmolality in the presence of maltose on the sorbitol production by Z. mobilis ATCC 29191.

\section{MATERIAL AND METHODS}

\section{Microorganism and fermentation medium}

Zymomonas mobilis ATCC 29191 was cultivated in sucrose medium $(\mathrm{g} / \mathrm{L}): 100$, yeast extract: $10 ; \quad\left(\mathrm{NH}_{4}\right)_{2} \mathrm{SO}_{4}: \quad 1 ; \quad \mathrm{KH}_{2} \mathrm{PO}_{4}: \quad$; $\mathrm{MgSO}_{4} .7 \mathrm{H}_{2} \mathrm{O}: 0.5 ; \mathrm{FeSO}_{4}$ : 0.5; peptone: 5 . After a $20 \mathrm{~h}$ (exponential phase) the cells were centrifuged at $7000 \mathrm{rpm}$. Sucrose and maltose were used in the experiment at concentrations stipulated in the experimental design (Table 1) with inoculum of $2 \mathrm{~g} / \mathrm{L}$ at a constant temperature of $30^{\circ} \mathrm{C}$ under batch condition. The times of fermentation evaluated were 12 and $36 \mathrm{~h}$.

\section{Statistical analysis}

The conditions tested to verify the effect of maltose on the sorbitol production are presented in Table 1. The design matrix building according Barros Neto et al. (1996), presented the experiments in the so-called standard order (Table $1)$.

Table 1 - Experimental design for full factorial $2^{3}$.

\begin{tabular}{ccccccc}
\hline \multirow{2}{*}{ Tests } & \multicolumn{3}{c}{ Coded Variables } & \multicolumn{3}{c}{ Decoded Variables } \\
\cline { 2 - 7 } & $\mathbf{X}_{\mathbf{1}}$ & $\mathbf{X}_{\mathbf{2}}$ & $\mathbf{X}_{\mathbf{3}}$ & Maltose $(\mathbf{g} / \mathbf{L})$ & Sucrose $(\mathbf{g} / \mathbf{L})$ & Time $(\mathbf{h})$ \\
\hline 1 & -1 & -1 & -1 & 0 & 200 & 12 \\
2 & 1 & -1 & -1 & 100 & 200 & 12 \\
3 & -1 & 1 & -1 & 0 & 300 & 12 \\
4 & 1 & 1 & -1 & 100 & 300 & 12 \\
5 & -1 & -1 & 1 & 0 & 200 & 36 \\
6 & 1 & -1 & 1 & 100 & 200 & 36 \\
7 & -1 & 1 & 1 & 0 & 300 & 36 \\
8 & 1 & 1 & 1 & 100 & 300 & 36 \\
\hline
\end{tabular}

The results were analyzed by means of the STATISTICA software version 5.1 (Experimental Design) for microinformatics. The objective was to verify which contrasts were statistically significant, particularly those concerning the main effects.

\section{Analytical procedures}

Biomass determinations were performed by means of turbidimetry at $605 \mathrm{~nm}$ and related to dry weight through a standard curve. Sorbitol was determined by HPLC using CLC-NH2 (ShimPack) (9 um, $30 \mathrm{~cm} \mathrm{x} 1.6 \mathrm{~cm}$; at $55{ }^{\circ} \mathrm{C}$ ) and water 
as eluent $(1 \mathrm{ml} / \mathrm{min})$. Detector Refraction Index was used to detect sorbitol. Reducing sugars (RS) and total reducing sugars (TRS) were determined by Somogy (1945) and Nelson (1944).

\section{RESULTS AND DISCUSSION}

Sorbitol production by Zymomonas mobilis is attributed to the osmoprotective effect of sorbitol on the microorganism under osmotic stress conditions due to the high concentration of sugars and other compounds present in the culture medium. The results obtained by the work on the osmotic stress caused by the high sucrose concentration and the addition of maltose in the sorbitol production are presented in Table 2, and the effects related to factors time and concentration are described in Table 3.

Table 2 showed that in total sugar concentrations from 200 to $400 \mathrm{~g} / \mathrm{L}$, there was no positive correlation with the sorbitol production. A considerable drop in the sorbitol formation was rather observed with the increase in the concentration of sugars in the medium, thus decreasing its production from 38.60 to $20.61 \mathrm{~g} / \mathrm{L}$ when the sugar concentration increased from 300 $\mathrm{g} / \mathrm{L}$ of sucrose to $300 \mathrm{~g} / \mathrm{L}$ of sucrose $+100 \mathrm{~g} / \mathrm{L}$ of maltose in $36 \mathrm{~h}$ cultivation, probably due to the excessive increase in osmotic pressure.

Table 2 - Biomass and sorbitol production in relation to changes on substrate concentration and time according to experimental design $2^{3}$.

\begin{tabular}{|c|c|c|c|c|c|}
\hline \multirow{2}{*}{ Tests } & Sucrose & Maltose & Time & Biomass & Sorbitol \\
\hline & $(g / L)$ & $(g / L)$ & (h) & $(g / L)$ & $(\mathrm{g} / \mathrm{L})$ \\
\hline 1 & 200 & 0 & 12 & 2.27 & 34.66 \\
\hline 2 & 200 & 100 & 12 & 2.66 & 34.84 \\
\hline 3 & 300 & 0 & 12 & 2.7 & 31.915 \\
\hline 4 & 300 & 100 & 12 & 2.74 & 15.925 \\
\hline 5 & 200 & 0 & 36 & 2.32 & 34.03 \\
\hline 6 & 200 & 100 & 36 & 2.65 & 38.07 \\
\hline 7 & 300 & 0 & 36 & 2.69 & 38.68 \\
\hline 8 & 300 & 100 & 36 & 2.54 & 20.61 \\
\hline
\end{tabular}

Responses are averages between two true replications, $\mathrm{R}^{2}=95.35, \mathrm{X}_{1}=$ sucrose $(\mathrm{g} / \mathrm{L}), \mathrm{X}_{2}=$ maltose $(\mathrm{g} / \mathrm{L})$

$\mathrm{X}_{3}=$ time $(\mathrm{h})$.

Table 3 - Estimation of the effects related to factors sucrose, maltose and time on the experimental design $2^{3}$.

\begin{tabular}{lcc}
\hline Factor & Effect & P \\
\hline Average/Intercession & $31.09^{*}$ & $0^{* *}$ \\
Block & $-2.10(\mathrm{~ns})$ & $0.12(\mathrm{~ns})$ \\
$\mathrm{X}_{1}$ & $-7.46^{*}$ & $0.0003^{* *}$ \\
$\mathrm{X}_{2}$ & $-8.62^{*}$ & $0.0001^{* *}$ \\
$\mathrm{X}_{3}$ & $3.51^{*}$ & $0.02^{*}$ \\
$\mathrm{X}_{1} \cdot \mathrm{X}_{2}$ & $-9.57^{*}$ & $0.00005^{* *}$ \\
$\mathrm{X}_{1} \cdot \mathrm{X}_{3}$ & $0.44(\mathrm{~ns})$ & $0.73(\mathrm{~ns})$ \\
$\mathrm{X}_{2} \cdot \mathrm{X}_{3}$ & $2.21(\mathrm{~ns})$ & $0.11(\mathrm{~ns})$ \\
\hline
\end{tabular}

$\mathrm{X}_{1}=$ maltose concentration; $\mathrm{X}_{2}=$ sucrose concentration; $\mathrm{X}_{3}=$ time; $\mathrm{R}^{2}=0$.

The effects of sucrose, maltose and cultivation time are showed in Table 3. Evidently the three factors $\left(\mathrm{X}_{1}, \mathrm{X}_{2}\right.$ and $\left.\mathrm{X}_{3}\right)$ as well as the interaction $\mathrm{X}_{1} \cdot \mathrm{X}_{2}$ present significant effects on the sorbitol production. However, $\mathrm{X}_{1}$ (sucrose concentration) and $X_{2}$ (maltose concentration) presented negative effects and their respective increases caused reduction on the sorbitol levels. The determination coefficient $\left(\mathrm{R}^{2}\right)$ indicated that $95.35 \%$ of the variation could be attributed to the model. Figure 1 represents the model for sorbitol when the cultivation time was fixed in $36 \mathrm{~h}$. The highest sorbitol productions were at regions with levels below $\mathrm{X}_{1}$ (sucrose) and $\mathrm{X}_{2}$ (maltose). However, since concentrations higher than $300 \mathrm{~g} / \mathrm{L}$ of sucrose was not studied, it was not possible to confirm if the decrease in the production occurred due the addition of maltose or by high osmotic pressure. 
Besides, it was not possible to conclude that sucrose would have the same effect considering that it was metabolizable by Z. mobilis and maltose not.
Table 3 showed that the effect of factor $X_{3}$ (time) was significant and positive; therefore, increases on this factor would cause increases on the sorbitol levels.

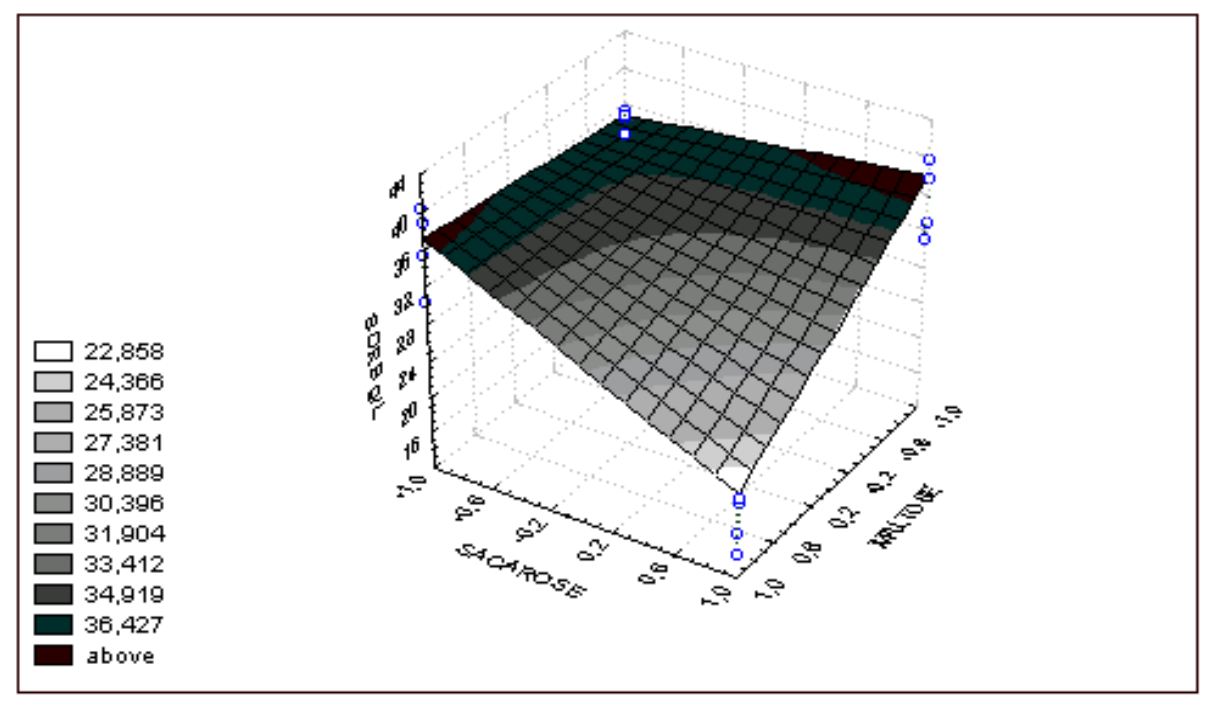

Figure 1 - Sorbitol production as a result of the Z. mobilis ATCC 29191 fermentation in 36 h of cultivation.

However observing the production on Table 2, it was possible to conclude that the time contribution was not superior to $10 \%$ considering the cultivation with $200 \mathrm{~g} / \mathrm{L}$ of sucrose $+100 \mathrm{~g} / \mathrm{L}$ of maltose and $21 \%$ considering $300 \mathrm{~g} / \mathrm{L}$ of sucrose, conditions where the time effect was more pronounced. Barros et al. (2006) found an optimum production in $36 \mathrm{~h}$ culture with $200 \mathrm{~g} / \mathrm{L}$ of sucrose. Vignoli et al. (2005) observed that the sucrose concentration did not influence sorbitol production by the immobilized culture but increase in the culture time increased sorbitol levels. Permeabilized cells of Zymomonas mobilis also achieved maximum production sorbitol in $36 \mathrm{~h}$ of fermentation (Vignoli et al., 2006). Probably, due the high concentration of sugars, the microorganism needed a longer time to metabolize it.

Although the general effect of the high sugar concentration was negative, the sorbitol production remained unchanged at $300 \mathrm{~g} / \mathrm{L}$, regardless if the sugar was sucrose or sucrose associated with maltose. Considering that the osmotic pressure in the media with $200 \mathrm{~g} / \mathrm{L}$ of sucrose $+100 \mathrm{~g} / \mathrm{L}$ of maltose and $300 \mathrm{~g} / \mathrm{L}$ sucrose was practically the same, it was expected that the sorbitol production was similar (Table 2), thus corroborating the osmoprotective effect of sorbitol at high sugar concentrations, as mentioned by Bekers et al. (2000). Furthermore, the increase in the substrate concentration from 200 to $300 \mathrm{~g} / \mathrm{L}$ increased the sorbitol production by $12 \%$, regardless if the sugar was sucrose or sucrose associated with maltose. Cazetta et al.(2005) reported a maximum sorbitol production for medium containing molasses at $300 \mathrm{~g} / \mathrm{L}$ of sugars by Z. mobilis ATCC 29191; there was a sharp fall the in production when the sugar concentration was below or above $300 \mathrm{~g} / \mathrm{L}$. Barros and Celligoi (2006) also obtained highest sorbitol production (60.46 g/L) by Z. mobilis ATCC 20191 on sucrose at $300 \mathrm{~g} / \mathrm{L}$ after $36 \mathrm{~h}$; there was significant decrease in sorbitol production when the medium was previously hydrolysed with invertase, probably due to the excessive increase in osmotic pressure. This showed that the high osmotic pressure caused a decrease on sorbitol production independent of sugar nature, metabolizable or not.

The effects of the osmolality on the culture medium are scarcely found in literature; however, 
some works using high sugar concentrations are available. Silveira et al. (1999) investigated the influence of the initial substrate concentration on equimolar glucose and fructose concentrations and found optimum sorbitol production at $650 \mathrm{~g} / \mathrm{L}$ of sugars. Although the high sugar concentration was optimum, a very high inoculum $(30 \mathrm{~g} / \mathrm{L})$ was also used, while an inoculum of $2 \mathrm{~g} / \mathrm{L}$ was used in the present work. Moreover, glucose and fructose are substrates that can be directly used by the GFOR enzyme, unlike sucrose that requires a prehydrolysis stage. Sasahara and Izumori (2005) also observed that the conversion rate of L-sorbitol from fructose by Aureobasidium pullulans was accelerated when erythritol or L-arabitol was added to the reaction mixture. Their results indicated that L-sorbitol production was facilitated in high concentrations of the substrate.

In relation to the biomass production, observed no increase from 12 to $36 \mathrm{~h}$ and that the increase on the substrate concentration did not produce changes on the biomass production either (Table 2 ). This could have occurred due to the high initial inoculum $(2 \mathrm{~g} / \mathrm{L})$ or due to the growth inhibition in function of the high sugar concentration employed. The inhibition of Z. mobilis growth due to the high glucose concentration is widely known. Erzinger (1996) reported a significant reduction on the growth and ethanol production when initial glucose concentrations above $150 \mathrm{~g} / \mathrm{L}$ were used.

The kinetic parameters obtained from the sorbitol production are presented in Table 4. Although the fermentation time led an increase on the sorbitol production, a decrease in specific productivity was observed after long periods, as expected. The highest productivity rates were approximately 2.8 and $2.9 \mathrm{~g} / \mathrm{L} \cdot \mathrm{h}^{-1}$ at $200 \mathrm{~g} / \mathrm{L}$ of sucrose and $200 \mathrm{~g} / \mathrm{L}$ of sucrose $+100 \mathrm{~g} / \mathrm{L}$ of maltose, respectively in a $12-\mathrm{h}$ cultivation. However, within $36 \mathrm{~h}$, these productivities dropped to 0.95 and $1.06 \mathrm{~g} / \mathrm{L} . \mathrm{h}^{-1}$, respectively. Silveira et al. (1999) reported higher GFOR stability in the processes using shorter times, where a crescent production was observed up to $4 \mathrm{~h}$ of process. After this period, the production became stable and decreased, thus productivity was less influenced by the loss of activity of GFOR when fast processes were employed. Besides, the total reducing sugar consumption was more efficient with lower fermentation times $[89.18 \%(12 \mathrm{~h})$ to $91.86 \%$ (36h)] in medium with $200 \mathrm{~g} / \mathrm{L}$ of sucrose. It was observed that the parameters productivity (Ypr) and product yield (Yps) showed more dependence on sugar concentration. A increase in sucrose and/or maltose in fermentation medium caused higher Ypr and Yps values.

Table 4 - Kinetic parameters obtained from the experimental design $2^{3}$ for the sorbitol production.

\begin{tabular}{ccccccccc}
\hline \multirow{2}{*}{ Tests } & Sucrose & Maltose & Time & TRS Consumption & $\mathbf{Y p r}$ & $\mathbf{Y p / s}$ & $\mathbf{Y p}$ \\
\cline { 2 - 8 } & $\mathbf{( g / L )}$ & $\mathbf{( g / L )}$ & $\mathbf{( h )}$ & $\mathbf{( \% )}$ & $\mathbf{( \% )}$ & $\mathbf{( g / g )}$ & $\left(\mathbf{g} / \mathbf{L . h} \mathbf{h}^{-\mathbf{1}}\right)$ \\
\hline 1 & 200 & 0 & 12 & 89.18 & 32.28 & 0.172 & 2.88 \\
2 & 200 & 100 & 12 & 50.38 & 61.18 & 0.33 & 2.9 & 2.66 \\
3 & 300 & 0 & 12 & 52.41 & 39.99 & 0.213 & 1.33 \\
4 & 300 & 100 & 12 & 18.61 & 55.19 & 0.29 & 0.95 \\
5 & 200 & 0 & 36 & 91.86 & 30.77 & 0.164 & 1.06 \\
6 & 200 & 100 & 36 & 70.11 & 48.04 & 0.253 & 1.07 \\
7 & 300 & 0 & 36 & 51.02 & 50.52 & 0.27 & 0.57 \\
8 & 300 & 100 & 36 & 19.7 & 67.46 & 0.36 & 0.57 \\
\hline
\end{tabular}

TRS: Total Reducing Sugars; Ypr: productivity; Yp/s: Product yield; Yp: specific productivity.

\section{CONCLUSION}

Considering the range of sugar concentration studied, a decrease in the sorbitol formation level was observed when the sugar concentration in the culture medium increased. However, within a preestablished range (from 200 to $300 \mathrm{~g} / \mathrm{L}$ ), the increase in the sugar concentration was followed by increases in the sorbitol, production probably as response to the necessity of an osmotic protection.
On the other hand, cultivation time maintained positive correlation with sorbitol production along the entire time interval studied, despite low increasing within the range studied.

\section{RESUMO}

Zymomonas mobilis produz o poliálcool sorbitol como principal subproduto. Sua formação é atribuída principalmente a sua função A produção 
de sorbitol foi avaliada através de um planejamento fatorial completo utilizando as variáveis concentração de sacarose, concentração de maltose e tempo de cultivo. A adição de açúcares causou um aumento na produção de sorbitol até a concentração de $300 \mathrm{~g} / \mathrm{L}$, porém decréscimos na produção de sorbitol foram observados a concentrações superiores a esta. Aumento no tempo de fermentação foi estatisticamente significativo para aumentos da produção de sorbitol, porém pequeno aumento foi observado de 12 para 36 horas de cultivo.

\section{REFERENCES}

Aldrich, H.C.; et al (1992), Immunocytochemical localization of glycolytic and fermentative enzymes in Zymomonas mobilis. J. Bacteriol. 174, 4504-4508.

Barros Neto, B.;. Scarmino, I.S; Bruns, E.R. (1996), Planejamento e Otimização de Experimentos, 2nd Edition., UNICAMP, 299 pp.

Barros, M.; Celligoi M.A.P.C., (2006), Synthesis of sorbitol by Zymomonas mobilis under high osmotic pressure. Braz. J. Microbiol. 37, 324-328.

Barros, M. et al. (2006), Influence of ultrasound on sorbitol release by Zymomonas mobilis grown on high sucrose concentration. Brazilian Archives of Biology and Technology, 49 (3), 371-374.

Bekers, M. et al. (2000), The effect of osmo-induced stress on product formation by $Z$. mobilis on sucrose. Int. J. Food Microbiol. 55, 147-150.

Cazetta, M.L. et al. (2005), Optimization study for sorbitol production by Zymomonas mobilis in sugar cane molasses. Process Biochem. 40, 747-751.

Doelle, M.B.; Greenfield, P.F.; Doelle, H.W. (1990), The relationship between sucrose hydrolysis, sorbitol formation and mineral ion concentration during bioethanol formation using Zymomonas mobilis 2716, Appl. Microbiol. Biotechnol. 34, 160-167.

Erzinger G.S. (1996), Influência da concentração de glicose e de etanol sobre a atividade de GFOR em Zymomonas mobilis ATCC29191, Master Thesis, Faculdade de Ciências Farmacêutica, Universidade de São Paulo, Brazil, 99pp.

Kannan, T. R., Sangiliyandi, G.; Gunasekaran, P. (1998), Improved ethanol production from sucrose by a mutant of Zymomonas mobilis lacking sucrases in immobilized cell formation. Enzyme Microbial. Technol. 22, 179-184.

Lin, J.J.; Dale, M.C.; Okos, M.R. (1991), Osmotic effects on growth and ethanol production of free an immobilized Zymomonas mobilis. Process Biochem. 26, 143-151.

Loos, H. et al, (1991), Localization of the glicosefrutose-oxidorreductase in wild type and overproducing strains of Zymomonas mobilis. FEMS Microbiol. Lett. 84, 211-216.

Loos, H. et al. (1994), Sorbitol promotes grown of Zymomonas mobilis in environmental which high concentrations of sugars: evidence for a physiological function of glicose-fructose-oxirreductase in osmoprotection. J. Bacteriol. 176, 7688-7693.

Loss, H.; Sahm, H.; Sprenger, G.A.(1993), Glicosefructose- oxidorreductase, a periplasmatic enzyme from Zymomonas mobilis, is active in its precursor form. FEMS Microbiol. Lett. 107, 293-298.

Nelson, N.A. (1944), A photometric adaptation of the Somogy method for determination of glucose, Biochem. 153, 375-380.

O’Mullan, P.; Szakacs-Dobozi, M. D.; Eveleigh, E. (1991), Identification of saccharolytic enzimes of $Z$. mobilis. Biotechnol. Lett. 13, 137-141.

Preziosi, L.; Michel, G.P.F.; Baratti, J. (1990), Sucrose metabolism in Zymomonas mobilis. Can. $J$. Microbiol. 36, 159-163.

Rogers, P.L. et al. (1982), Ethanol production by Zymomonas mobilis. Adv. Biochem. Eng. 23, 37-84.

Sasahara, H.; Izumori K.(2005), Production of Lsorbitol from L-fructose by Aureobasidium pullulans LP23 isolated from soy sauce mash. J. Biosci. Bioeng. 100 (2), 223-226.

Savvides, A.L. et al. (2000), Simultaneous ethanol and bacterial ice nuclei production from sugar beet molasses by a $Z$. mobilis $\mathrm{CP} 4$ mutant expressing the inaZ gene of Pseudomonas syringae in continuous culture. J. Appl. Microbiol. 89, 1002-1008.

Silveira, M.M. et al. (1999), Bioconversion of glucose and fructose to sorbitol and gluconic acid by untreated cells of Z. mobilis. J. Biotechnol. 75, 99103.

Somogy, M.A. (1945), A new reagent for determination of sugar, J. Biol. Chem. 160, 61-68.

Sprenger, G. A. (1996), Carbohydrate metabolism in Zymomonas mobilis: a catabolic highway with some scenic routes. FMS Microbiol. Lett. 145, 301-307.

Swings, J. J. De Ley.(1977), The biology of Zymomonas mobilis, Bacteriol. Rev. 41, 1- 46.

Vigants, A.; Zikmanis, P.; Bekers, M. (1996). Sucrose medium osmolality as a regulator of anabolic and catabolic parameters in Zymomonas culture. Acta Biotechnol. 16, 321-327.

Vignoli, J. A. et al, (2006). The production of sorbitol by permeabilized and immobilized cells of $\mathrm{Z}$. mobilis in sucrose. Brazilian Archives of Biology and Technology, 49 (4), 683-687.

Vignoli, J.A.; Celligoi, M.A.P.C.; Silva, R.S.F. (2005), Development of a statistical model for sorbitol production by free and immobilized Zymomonas mobilis in loofa sponge Luffa cilyndrica, Process Biochem. 41, 240-243.

Viikari, L. (1984), Formation of levan and sorbitol from sucrose by Zymomonas mobilis, Appl. Microbiol. Biotechnol. 19, 252-255. 
Viikari, L., Gisler, R. (1986), By-products in the fermentation of sucrose by different Zymomonas strains. Appl. Microbiol. Biotechnol. 24, 471-476.

Wiegert, T.; Sahm, H.; Sprenger, G.A.(1996), Export of the periplasmatic NADP-containing GFOR of Zymomonas mobilis. Arch. Microbiol. 166, 32-41.
Yanase, H et al. (1992), Purification, crystallization and properties of the extracellular levansucrase from Zymomonas mobilis, Biosci. Biotechnol. Biochem. 56, 1335-1337.

Received: March 26, 2008; Revised: September 03, 2008; Accepted: April 13, 2010. 